\title{
Development of the Carers' Alert Thermometer for Young Carers (CAT-YC) to Identify and Screen the Support Needs of Young Carers: A Mixed Method Consensus Study
}

\author{
Lynn Kettell $^{1}\left(\mathbb{D} \cdot\right.$ Mary R. O'Brien $^{1}(\mathbb{D}) \cdot$ Barbara A. Jack $^{1}(\mathbb{D}) \cdot$ Katherine Knighting $^{1}(\mathbb{D}$
}

Accepted: 29 August 2021 / Published online: 13 September 2021

(c) The Author(s) 2021

\begin{abstract}
This paper reports on a multi-phased, mixed-method consensus-based study conducted with young carers in the UK aged 11-18, and health, social care and education professionals from the UK, USA and Canada, to identify priority items for inclusion in a short screening tool for use with young carers of a family member with a progressive or long-term illness or disability. Following ethical approval from University and local Research Ethics Committees, qualitative and quantitative data were collected between 2017 and 2019 from 267 people (107 young carers; 160 professionals), through interviews, a focus group, a Delphi survey, consensus group meetings and consultations. Qualitative data were analysed thematically, and quantitative data were analysed using measures of central tendency, frequency and levels of dispersion. The resulting Carers' Alert Thermometer (CAT-YC) contains an identification question followed by ten areas of need across two themes of 'current caring situation' and 'carer's health and wellbeing,' along with guidance for possible next steps and space for an action plan to be jointly agreed between the screener and young carer. Preliminary piloting of the CAT-YC provides evidence of identifying and monitoring needs, and is expected to be useful for young carers, a wide range of professionals, and organisations that support young carers.
\end{abstract}

Keywords Young carers $\cdot$ Young caregivers $\cdot$ Needs assessment $\cdot$ Mixed-method $\cdot$ Screening tool $\cdot$ Delphi study

Internationally, estimates of young people providing informal care for a relative with a long-term illness, disability or addiction vary in different countries, but figures suggest it to be between 2 and $8 \%$ of all children in advanced industrialised capitalist societies (Leu \& Becker, 2017). However, this is a conservative measure, as often young people providing care remain hidden from formal statistics, perhaps due to them not self-identifying as carers (Carduff et al., 2014; Aldridge, 2017; Phelps, 2017). This could be because of the gradual or cumulative increase in the caring tasks they perform, or because they see their caring role as integral to the relationship they have with the person they care for (Carduff et al., 2014). Additionally, many more remain hidden due to fear of repercussions for their families in disclosing caring responsibilities, or from a sense of loyalty, fear of stigma

Lynn Kettell

Kettelll@edgehill.ac.uk

1 Faculty of Health, Social Care \& Medicine, Edge Hill University, Lancashire L39 4QP, UK or bullying, or simply because they are unaware of support available (Aldridge \& Becker, 1997; The Children's Society, 2013; Phelps, 2017).

Many of these hidden issues preventing young carers from seeking support are reported internationally; e.g. in the UK (Leu \& Becker, 2017), USA (Kavanaugh et al., 2015; Siskowski, 2006), Canada (Stamatopoulos, 2018), Australia (Moore \& McArthur, 2007) and New Zealand (Gaffney, 2007). Although young carers are often highly motivated to help their families, they may not recognise the emotional as well as physical toll the role can take on their health and wellbeing (Nagl-Cupal et al., 2014; Nicholls et al., 2016; Becker \& Sempick, 2018). Professionals therefore need to be proactive in asking what needs to be done if a young person's caring role compromises their health, education or social opportunities.

Lack of legal recognition of young carers is a global concern; e.g. in Canada there is no formal policy acknowledging, or recognising, young carers (Stamatopoulos, 2018). In Australia, although young people who provide unpaid care have been acknowledged in legislation, no mandatory 
protective services have been put in place to support any resultant needs they may have (McDougall et al., 2018). In the USA young carers, who are often referred to as 'young caregivers', have no specific legal rights (Kavanaugh et al., 2015), and Leu and Becker (2017, p. 757) argue that "to date, [in the USA] there has been little attention paid to the particular needs of young carers in policy or service responses." Current UK policies for supporting young carers place a duty on local authorities to take 'reasonable steps' to identify young carers who have support needs (Children's Commissioner, 2016, p. 6). Once identified, they must offer an assessment of their needs regardless of the amount or type of care they provide (Department of Health, 2014; Carers UK, 2016).

However, despite legislation, there is currently no national standardised assessment for young carers in the UK (The Children's Society, 2016; Aldridge, 2017) and assessments are often outsourced to non-governmental organisations in the third sector (Leu \& Becker, 2017). Arguably, many professionals are unaware of the specific legal requirements placed upon them, resulting in a gap between the ambition and purpose of the law, and the actual implementation on the ground by professionals (such as social workers, healthcare practitioners and teachers) with responsibilities in this area (Leu \& Becker, 2017). Consequently, even with a welldeveloped legal structure and framework, such as is in place in the UK, young carers may fall through the gaps in policy and legal safety nets (Aldridge, 2017). It is therefore imperative that young people providing care are identified, screened and assessed on a regular basis for any needs they may have due to their caring role.

\section{Background}

An integrative review of published studies (1993-2019) of existing screening and assessment tools created for use with young carers was undertaken to ascertain which tools are used to aid professionals working with young carers. This identified nine tools from eight studies undertaken in three different countries (UK, Australia, New Zealand), confirming that research on young carer difficulties and assessment is an international issue. Although there were positive factors in most of the studies reviewed, there were also limitations, particularly regarding a lack of consultation with young carers, and a lack of validity and reliability data in some of the studies. Only one of the tools was designed to aid identifying hidden young carers (Aldridge, 2014), and many of the studies reviewed utilised data from young carers covering a very broad age range, e.g. 9-35 (Pakenham et al., 2006). This is unlikely to be representative of the majority of young carers, as clearly the needs of young carers and young adult carers at the two extremes of the scale will be conceivably different. None of the tools in the studies reviewed offered signposting or suggestions for possible further assessments, actions or interventions. Moreover, none of the studies reviewed reported how long it took, or was likely to take, to administer the tools once developed.

In order to understand more about the screening and assessment processes commonly used with young carers in the UK, a brief scoping exercise was undertaken in 2018 with professionals from a variety of UK national young carers' organisations. The key issues highlighted were the lack of consistency between different organisations, both with regards to the tools used and the screening and assessment procedures followed. Moreover, none of the representatives reported their organisations had involved young carers in the development or design of their tools or procedures. Further inconsistencies related to waiting times for assessment, with one organisation confirming it could take in excess of six months from referral to assessment. As highlighted earlier, many young carers do not recognise their role until it is identified by school staff, social services, or health care professionals involved in the care of their ill or disabled family member, or at crisis (Aldridge, 2017; Phelps, 2017). Therefore, it is imperative that once identified, a needs assessment is conducted expeditiously, in order to prevent or minimise any negative impact resulting from the caring role. Consequently, screening and triaging according to need should be a necessary and important part of the assessment process.

Given the increasing economic and time constraints placed on professionals working with young carers, it is imperative that any screening tool developed is short, easy to use, has suggestions for next steps and includes priority areas to be reviewed on a regular basis. Importantly, it must be developed collaboratively with young carers and professionals, to ensure the items and information it contains are relevant to both groups. This paper presents a detailed description of how a sequential, exploratory, multi-phased, consensus-based approach was used to identify priority areas of need, as decided by the groups, and develop them into a short screening alert tool, the Carers' Alert Thermometer for Young Carers (CAT-YC).

\section{Methods}

The CAT-YC was developed using a modified four-round Delphi survey technique that collected, analysed and integrated qualitative and quantitative data sequentially from two cohorts of participants, young carers and professionals, between October 2017 and April 2019. The Delphi method was chosen for this study as it is a proven method to gain consensus over a number of successive rounds from 'expert' participants who are knowledgeable about the topic (McKenna, 1994 ;Jünger et al., 2017). Its strength lies in the 
premise that group opinion has greater validity than individual opinion (Keeney, 2015). It has been widely used in health care research to identify priorities for development of services, guidance and tools (e.g. Malcolm et al., 2009; Keeney, 2015). Prior to commencement, ethical approval for all phases of the study was granted by the University and local Research Ethics Committees. Informed consent and assent were obtained from participants throughout the study phases.

Each round of the Delphi had an explicit focus and Fig. 1 provides a summary of the methods and sample sizes for each round. The first round (R1) focused on item generation for the survey and was developed by thematically analysing data collected from semi-structured interviews and a focus group with young carers aged 11-18 in North West England. The second and third rounds (R2 and R3) used a structured approach to analyse data collected from questionnaires that were distributed either online for professionals, or at a series of small group meetings for young carers. Pre-determined criteria for consensus was used and any adaptations were based on the findings of the previous round (Jünger et al., 2017). In the Delphi rounds, the views of each of the two cohorts were treated equally in order to gain consensus from both cohort's perspectives on the key areas to include in the CAT-YC.

As the proposed tool needed to be suitable for practice, it was essential that national guidance on young carer support was considered to ensure it was fit for purpose. Moreover,
Fig. 1 Flowchart of the multiphase modified Delphi

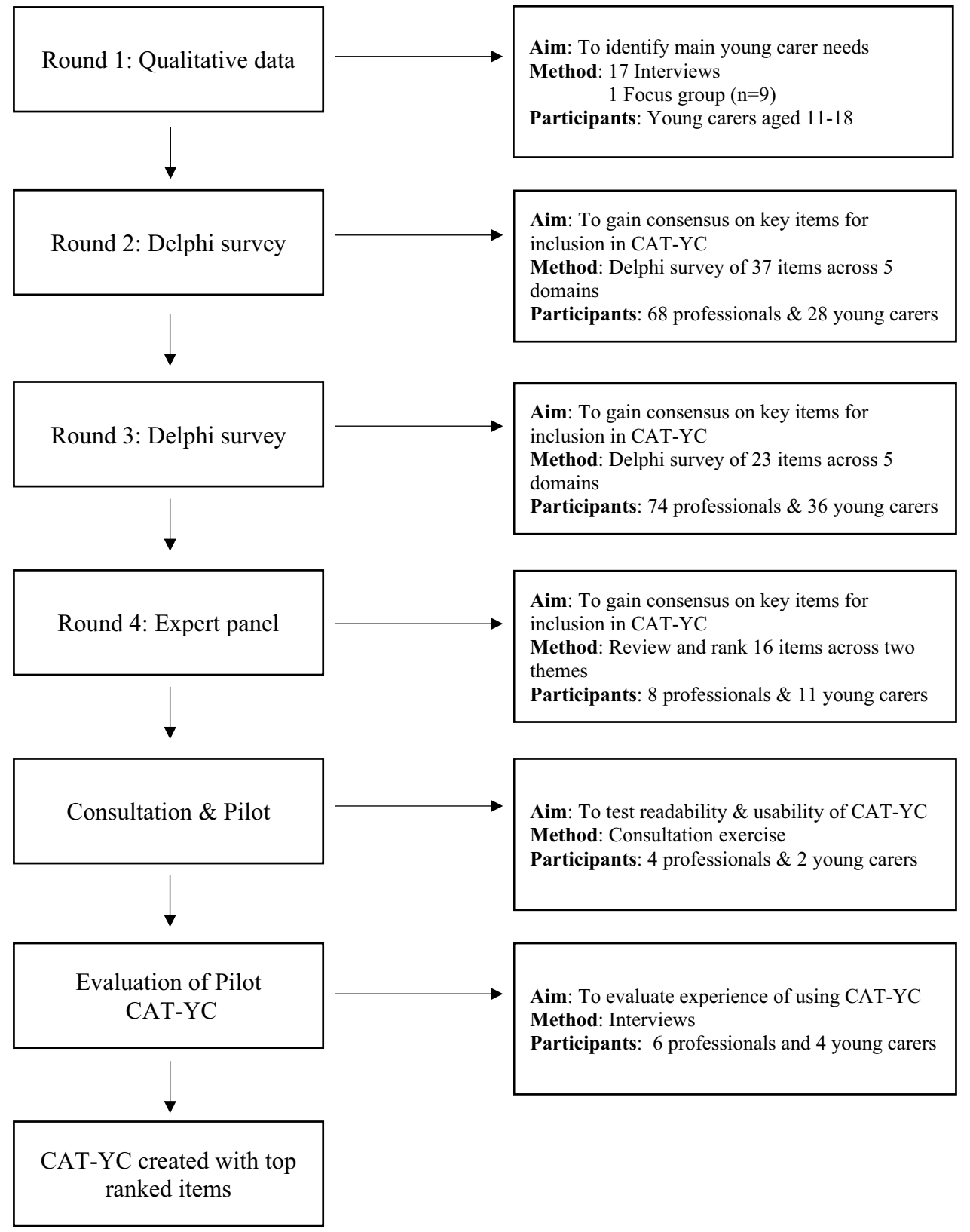


whilst the items in the CAT-YC were generated from issues raised by young carers, these were balanced with the views of those who will be involved with its administration, signposting and follow up of support or actions. Therefore, a fourth round (R4) consisting of analysing data collected from two groups, UK professionals with a strategic role in young carer support within national or regional organisations, and young carers, was used to further refine the final items for inclusion in the CAT-YC (Knighting et al., 2015, 2016). That said, young carers' voices were retained as much as possible, and they were asked to comment on key emerging findings throughout the study, in accordance with National Children's Bureau guidelines (Shaw et al., 2011).

A draft version of the CAT-YC was developed based on the Delphi findings, then reviewed by several young carers and professionals who were involved in earlier rounds of the study, to ensure the content was clear to understand by the parties most likely to use it. The young carers' centres involved in earlier phases of the study piloted the draft version of the CAT-YC for usability by their organisations. The organisational pilot phase was then evaluated to highlight and address any potential issues that were not foreseen in the developmental stage (Knighting et al., 2015, 2016; McKenna et al., 2015). The method and results for each phase of the study are outlined together in the results section, due to the iterative nature of the study.

\section{Results}

\section{Round 1: Item Generation}

Purposive sampling was used to recruit young carers aged 11-18, mainly from young carers' centres in North West England. Additionally, several participants were recruited from an organisation that works with young people who have a sibling with a life-limiting health condition, and a local university Service Users and Carers group. As levels of comprehension can vary substantially at different ages (Gibson, 2007; Stewart \& Shamdasani, 2014), separate information packs for two age groups, 11-15, and 16-18, were developed following consultation with several young people. Potential participants were identified by staff at the various groups and given the relevant information and recruitment packs about the study to take home and consider. All of the 26 recruited participants provided written assent or consent to take part, with those aged under 16 also providing written consent from their parent or guardian. The average age of the participants was 14.7 years, with 15 of the participants reporting their gender as female and 11 as male. In total, 12 participants lived in a household with two parents or legal guardians and 14 lived in a lone parent household. Fifteen of the care recipients were either one or more of the young carer's parents, eight care recipients were a sibling, and three were a combination of both.

Seventeen individual interviews were conducted at either a young carers' centre or support group, or for those who were not members of a young carers' centre, at their family home. Data collected from those interviews provided a balance to data collected via participants at dedicated young carers' groups, as different perspectives and experiences were given, thereby reducing any potential for bias from purposive sampling at those sites (Bryman, 2016; Polit \& Beck, 2017). Additionally, a focus group comprising of nine participants aged 12-14 was held at one of the venues. A semi-structured guide was used for data collection (see Table 1) and data were digitally recorded and transcribed verbatim. Information about support services was provided to all participants.

\section{Round 1 Data Analysis and Survey Development}

A thematic analysis approach was used to develop themes identified in the interview and focus group data (Braun \& Clarke, 2006). Two main overarching themes were identified: the young carers' situation and caring role within the family home; and their own health and wellbeing. Key factors in the themes were discussed, reviewed and refined by all members of the research team. Further development of the themes identified five sub-themes, or domains, as identified in Fig. 2. In order to reduce potential bias from collecting data from one regional area in the UK, existing literature was revisited to ensure the items developed for the survey were comprehensive. Altogether, 37 items (questions) were developed from the five domains for R2 of the Delphi survey. The purpose of the next rounds of the survey was for young carers aged 11-18 and relevant health, social care and education-based professionals, to rate the importance of the items and begin the process of reaching consensus on the most important items to be included in the CAT-YC. Respondents were asked to rate the items on a Likert scale from (1) 'not at all important' to (5) 'extremely important.' A comment box was provided next to each domain to allow respondents to express any issues, or to highlight any items they felt were missing from the CAT-YC. A separate demographics section was added to the survey to capture relevant information about the respondents. Additionally, a final section was added, asking respondents whether they felt it was important for young carers' needs to be assessed, and if so, how often they should be reviewed. Respondents for the next round of the survey were also asked to choose from a multiple-choice list of who they felt should carry out screenings and assessments. Finally, respondents were asked to rank the five domains according to their perception of least to most important (Knighting et al., 2015, 2016). The survey was created online using SurveyMonkey® and was also available 
Table 1 Round 1 topics and questions in the semi-structured guide

\begin{tabular}{|c|c|}
\hline Demographics & $\begin{array}{l}\text { a) Age } \\
\text { b) Family composition (who they live with; if they have younger/older siblings) } \\
\text { c) Who they help care for } \\
\text { d) How long they have been caring for their family member } \\
\text { e) Do they know why their family member needs care }\end{array}$ \\
\hline Perception of young carers & $\begin{array}{l}\text { a) If you had to describe what being a young carer means to you, what would you say? } \\
\text { b) Do you think other people would describe young carers in the same way? (family? friends? teachers?) }\end{array}$ \\
\hline Current caring role & $\begin{array}{l}\text { a) Can you tell me what sorts of things you do as a young carer for ...? (practical things, emotional support, day to } \\
\text { day things) } \\
\text { b) How much time does this take? (daily/weekly - does this ever change?) } \\
\text { c) How does being a young carer affect your life? (home? school? friendships? hobbies?) } \\
\text { d) How do you deal with these things? (practical ways? help from others?) }\end{array}$ \\
\hline Self-esteem & $\begin{array}{l}\text { a) How do you feel about being a young carer? (can you think of any words to describe how you feel?) } \\
\text { b) What are the good things about being a young carer? (anything you enjoy? feel good about?) } \\
\text { c) And the not so good things? (anything you find difficult? struggle with?) }\end{array}$ \\
\hline Support & $\begin{array}{l}\text { a) What things help you now in your caring role? (what makes a difference? easier? home/school/young carers' } \\
\text { group?) } \\
\text { b) Do many people know you are a young carer? (friends? teachers?) } \\
\text { c) What things would help you more? (at home? school?) }\end{array}$ \\
\hline Assessments & $\begin{array}{l}\text { a) Have you had a young carers assessment? (someone asking you about your needs as a young carer?) } \\
\text { b) (If yes) When did you have this? (who did it? how long did you wait? did anything change?) }\end{array}$ \\
\hline Open-ended question & $\begin{array}{l}\text { Is there anything else you want to say? (anything important I might have missed? anything you weren't sure of? any } \\
\text { last words?) }\end{array}$ \\
\hline
\end{tabular}

Fig. 2 Themes and sub-themes (domains) for R1
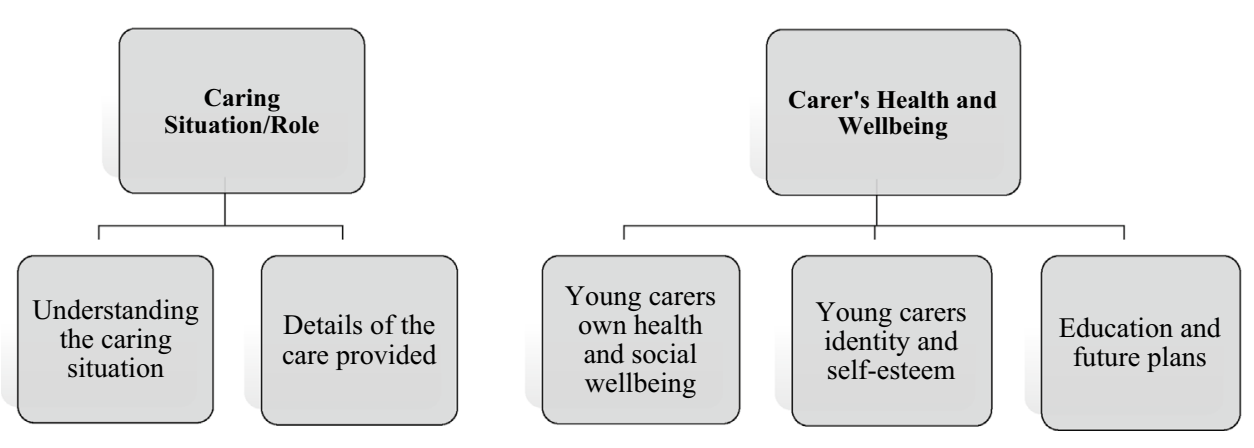

in paper format. Prior to launching the survey, a small pilot study to check readability and usability was undertaken with professionals and young carers $(n=6)$ at organisations who had taken part in $\mathrm{R} 1$, as recommended for Delphi studies by Novakowski and Wellar (2008).

\section{Round 2}

A purposive sampling approach was used to recruit young carers aged 11-18 and professionals working with young carers. Emails with information about the study and an invitation to participate were sent out to 142 national young carers' organisations and charities known to support young carers for inclusion in newsletters. Staff at those organisations were asked to cascade information to other relevant professionals and young carers aged 16-18, as appropriate (Hunt \& Lathlean, 2015). Furthermore, the social media site Twitter was used to advertise the study. However, social media was not used to recruit young carers aged 11-15, due to guidelines recommending that young people under 14 should not have social media accounts (Schurgin \& ClarkePearson, 2011; UK Council for Child Internet Safety, 2016). Therefore, a purposive sampling approach was used to recruit young carers aged 11-15 to take part in small consensus group meetings, via young carers' support groups and a national charity supporting young carers (Green \& Thorogood, 2014; Bryman, 2016). Using such an approach, in tandem with the Delphi process, ensured that all invited young carers who wished to participate had the opportunity to complete the survey and provide information and feedback in a supportive environment (Bailey et al. 2015).

The R2 survey was completed in July 2018 by 68 professionals and 28 young carers $(n=96)$. The professionals consisted of a range of staff working either directly or indirectly with young carers, in the paid and voluntary sectors. The average age of the young carers was 14.4 and more than 
half of them reported providing care for 21 or more hours per week. The majority of respondents (18) primarily cared for their mother, five cared for their father, three cared for a sibling and two cared for a grandparent. The main reasons for their family member needing care were due to a mental health condition (57\%), a physical health condition (39\%) or a physical disability (32\%), although some respondents selected more than one reason. The same methods of analysis were used for both the online Delphi surveys and consensus group surveys. Qualitative data were analysed thematically, as in R1 (Braun \& Clarke, 2006). Quantitative data were entered into the IBM SPSS Statistics, Version 25, for analysis (Armonk, NY; IBM Corp, 2017). Descriptive statistics, relating to profession (for professionals), or age, gender and length of time as a carer (for young carers), were used to describe the samples according to the demographic information gained from the surveys (Field, 2013; Bryman, 2016). Data concerning the collective judgements of the respondents were analysed using measures of central tendency, frequency and levels of dispersion (Field, 2013). The following pre-determined consensus criteria were used:

\section{Criterion to Accept an Item}

At least $60 \%$ of the young carer and professional cohorts rated an item as (4) (very important) or (5) (extremely important). Accepted items were removed from the survey for the next round as they did not require any further rating.

\section{Criterion for Re-Rating an Item}

If $60 \%$ of one cohort rated an item as (4) (very important) or (5) (extremely important) but the other cohort did not, suggesting disagreement between cohorts, they were retained for re-rating in R3.

\section{Criterion for Rejecting an Item}

Any items that did not meet the $60 \%$ criterion in the total sample were removed from the survey.

Altogether, 13 items met the criterion for acceptance, one item was rejected, and 23 items were retained for re-rating in R3.

\section{Round 3}

The same sampling strategy and data collection method used in the previous round was used for R3. Additionally, controlled feedback was given for the remaining 23 items using the group median score to show respondents the level and range each item was rated at previously (Keeney et al., 2011). Items that had reached consensus in R2 did not form part of the survey for R3 but were displayed under each domain as a reminder of what had been previously accepted (Keeney et al., 2011).

The R3 survey was completed in October 2018 by 74 professionals and 36 young carers $(n=110)$ and data were analysed quantitatively and qualitatively as in R2. Demographic results were similar to those in R2, as many of the respondents were likely to have been the same individuals. The same criterion for acceptance was used, resulting in an additional 13 items to be added to the previously accepted items from R2. As in R2, one item met the rejection criteria and was therefore immediately rejected. There was still disagreement between the cohorts for nine items. Therefore, as consensus had not been achieved after both rounds, these items were also rejected, in accordance with the predetermined consensus criteria (McKenna et al., 2015). The mean and standard deviation (SD) were calculated for each of the 26 items that reached consensus in R2 and R3 in order from 'most important' to 'least important' (McKenna et al., 2015). The items were then sent for a fourth round to an expert panel in January 2019, to comment on the list of top ranked items from the Delphi survey findings and choose and rank a final list of ten items. The rationale for having ten items was based on the pragmatic need to not overburden young carers or professionals working with them by having too many questions in the CAT-YC.

\section{Round 4}

The expert panel comprised of eight professionals from national or regional organisations that have a key strategic role in young carer support, and eleven young carers aged 16-18 who were identified and approached by gatekeepers at organisations that took part in earlier phases of the study. The rationale for only including young carers aged 16-18 was based on the panel being conducted virtually, and as reported earlier, young carers aged 11-15 were not approached or encouraged to take part in the study online (UK Council for Child Internet Safety, 2016). The items were listed in a three-section survey created through SurveyMonkey®, with separate demographic sections for each cohort. The first section asked participants to review the list of items and domains and provide feedback. The second section asked participants to choose and rank their top ten items; the final section asked who should use the CAT-YC and how often, and for demographic details to be provided.

Overall, there was a high level of consensus between both the professional and young carer cohorts, with each cohort ranking the same eight items in their top ten. It is interesting to note that three of the items were from Domain 1 (Understanding the Caring Situation), three from Domain 2 (Details of the Care Provided by the Young Person), three from Domain 3 (The Young Carers Own Health and Social Wellbeing), none from Domain 4 (The Young Carers 
Identity and Self-Esteem) and one from Domain 5 (Education and Future Plans).

Feedback was very positive about the comprehensiveness of the items:

Very comprehensive [...] appears holistic and should be suitable for all professionals to use (Professional-06)

I felt like all the items should definitely be included (Young Carer-04)

Participants in the expert panel were asked their views of how often the needs of young carers should be reviewed, as a minimum. 'Every six months' was the option most frequently selected by participants from both cohorts, with almost half of the participants overall choosing this option. Table 2 shows the results of who participants felt should be responsible for using the CAT-YC with young carers.

\section{Creation of the CAT-YC}

Prior to consulting with professionals and young carers, an initial draft version of the CAT-YC was created, based on similar design principles to those of the original Carers' Alert Thermometer (CAT) for adult carers (Knighting et al., 2015, 2016). The first section of the draft CAT-YC was developed to include space for the young carer's demographic information, education details, parent or guardian's contact details, family composition and basic pertinent information about the person they care for. The second section contained an initial identifying question to ascertain if the young person was providing care for a family member and if so, whether they shared care with another person. This was followed by a question asking them to rate, using a traffic light system of green (low), amber (medium) or red (high) emojis, how much help or support they needed with each of the top ten items from the findings in the Delphi survey, as shown in Table 3. Section three contained an alert thermometer to record the number of high or medium alerts, thereby providing a visual overview of the areas needing an urgent response or monitoring. Section four had a 'suggested next steps' section for staff, with space to include appropriate guidance for addressing each item scoring a high or medium alert. Section five had space to record up to three priority alerts requiring action, together with boxes for any immediate action taken, next steps, name of the person responsible for following up the action and a date for when the action would be followed up. The final section had space for when and who would conduct the next review, information regarding consent for use of data and space for the young carer's signature. Similarly, a user guide for staff was developed to explain how to administer and complete each section of the tool. Information was also included in the guide to remind practitioners to refer to any appropriate safeguarding policies and to discuss storage and sharing of the CAT-YC, according to their own organisational policies and procedures.

\section{Consultation and CAT-YC Pilot Evaluation}

Gatekeepers at organisations who had taken part in previous phases of the study were approached in March 2019 and invited to take part in a brief validity pilot to test the readability and usability of the CAT-YC. First, four members of staff and two young carers $(n=6)$ took part in a consultation exercise. Following this, slight changes and refinements were made to the layout of the CAT-YC, which is on one double-sided sheet of A4. The CAT-YC was then piloted in April 2019 by three organisations working with young carers in North West England. Semistructured interviews were conducted with staff $(n=6)$ and young carers $(n=4)$ to explore their experiences and views of using it. Staff who took part had a mean average of eight years of experience working with young carers; young carers were aged 15-17 and had a mean average of four years of experience in their caring role. Data from the

Table 2 Views on which professionals should use the CAT-YC (Expert Panel)

\begin{tabular}{|c|c|c|c|c|}
\hline \multicolumn{2}{|c|}{ Professionals occupations } & \multirow{2}{*}{$\begin{array}{l}\text { Total sample n (\%) } \\
10(53 \%)\end{array}$} & \multirow{2}{*}{$\begin{array}{l}\text { Professionals n (\%) } \\
5(63 \%)\end{array}$} & \multirow{2}{*}{$\begin{array}{l}\text { Young carers n }(\%) \\
5(45 \%)\end{array}$} \\
\hline 1 & Carers' centre staff & & & \\
\hline 2 & Social worker & $13(68 \%)$ & $6(75 \%)$ & $7(64 \%)$ \\
\hline 3 & Teachers & $9(47 \%)$ & $5(63 \%)$ & $436 \%)$ \\
\hline 4 & Anyone who has contact with young carers & $10(53 \%)$ & $5(63 \%)$ & $5(45 \%)$ \\
\hline 5 & Other school staff & $11(58 \%)$ & $5(63 \%)$ & $6(55 \%)$ \\
\hline 6 & G.P & $11(58 \%)$ & $6(75 \%)$ & $5(45 \%)$ \\
\hline 7 & Practice nurse & $5(26 \%)$ & $4(50 \%)$ & $1(9 \%)$ \\
\hline 8 & School nurse & $11(58 \%)$ & $6(75 \%)$ & $5(45 \%)$ \\
\hline 9 & Adult worker supporting the parent & $13(68 \%)$ & $7(88 \%)$ & $6(55 \%)$ \\
\hline 10 & Other & $3(16 \%)$ & $2(25 \%)$ & $1(9 \%)$ \\
\hline
\end{tabular}

*Participants could choose more than one option 
Table 3 Top ten items for inclusion in the CAT-YC

\section{SECTION 2: IDENTIFY \& SCREEN YOUNG CARER'S NEEDS}

Do you currently have any needs or concerns about looking after someone in your family who needs support, or about your own health and well-being? (please tick one) Yes $\square \quad$ No $\square \quad$ Unsure $\square$

If yes, does anyone else in the family share caring responsibilities with you? (please tick one) Yes $\square$ No $\square$

(If no needs raised with this opening question continue with the rest of the CAT-YC. If there are needs raised, listen to them now before progressing with the CAT-YC, as it will help to guide you about the young carer's priorities)

Complete the questions together and circle the level of need or perceived need the young carer has using:
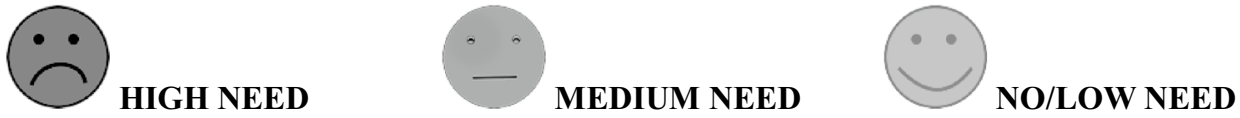

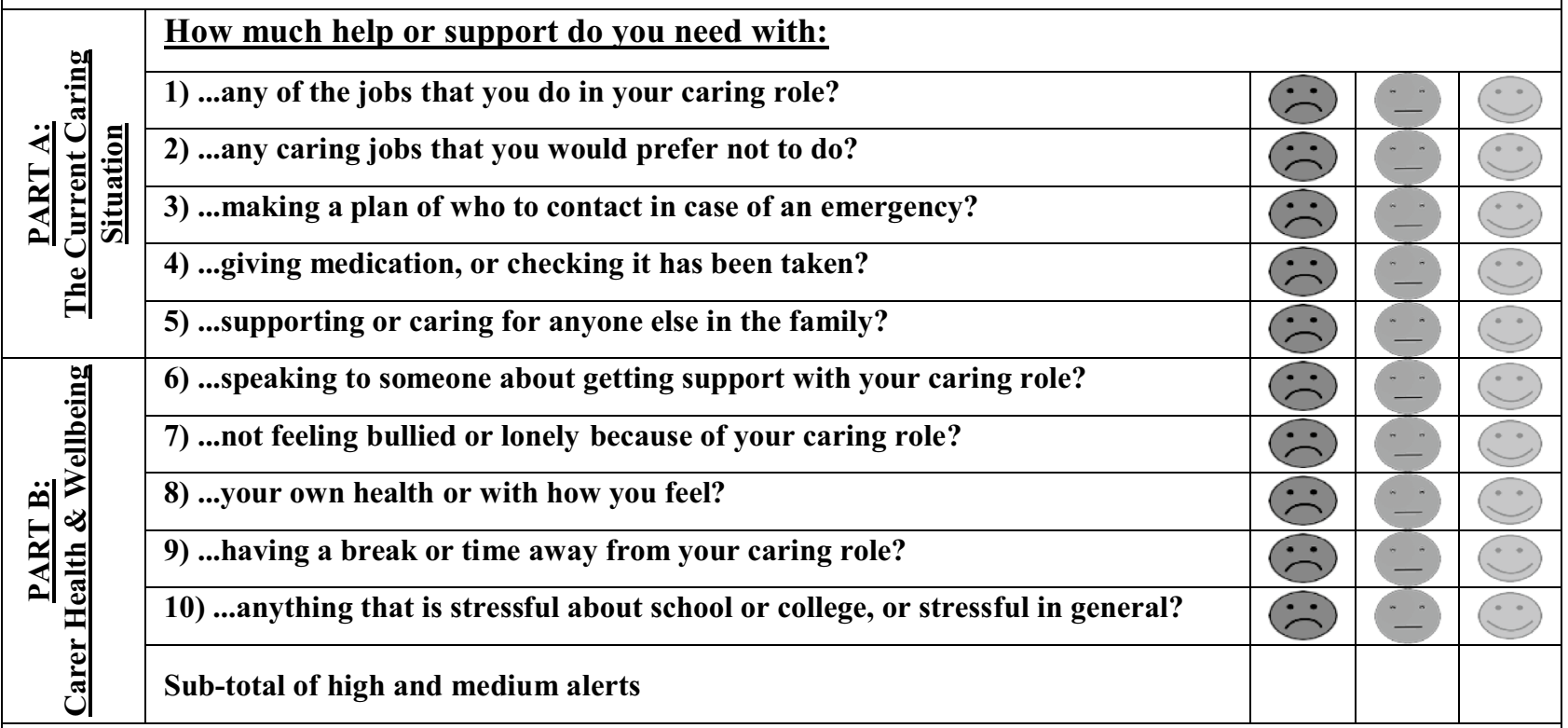

Check if there is anything else the young person wants to talk about or raise as a concern, or wishes to record themselves on the CAT-YC (make notes overleaf as appropriate)

\begin{tabular}{|c|c|c|c|c|}
\hline How able do you feel to continue providing care at the current & $\begin{array}{c}\text { Not Very } \\
\text { Able }\end{array}$ & & & Able \\
\hline level for the person/people? (please circle one number on the scale) & 2 & 3 & 4 & 5 \\
\hline
\end{tabular}

interviews were transcribed and analysed using content analysis (Hsieh \& Shannon, 2005; Elo \& Kyngäs, 2008).

An evaluation of the findings indicated the CAT-YC was comprehensive, enabled discussion about issues of concern to the young carer, and would be a valuable tool to identify current as well as future areas of concern for the young carer. Participants liked the clear instructions and visual appearance of the CAT-YC. In particular, one staff member commented on how the young carers appreciated the use of red, amber and green emojis to indicate high, medium and low levels of need in section two:
It was easy to fill in and the young people liked the faces, rather than having the tick box in the forms we currently use - it's good that it measures the level, rather than just yes/no (Staff 4)

Similarly, the practical focus of the CAT-YC was unanimously liked, particularly with regards to recording action points and accountability:

The action plan was nice to finish off with...it felt like something was happening, not just talking about it (Young Carer 2) 
Particularly liked Section 5, especially for older young carers...who is responsible and the date, so the young person has it in their head what's going to happen (Staff 1)

During the pilot study period, the CAT-YC successfully identified a number of alerts. Consequent actions included practical solutions, e.g. contacting school about a bullying situation, helping a young carer create a $\mathrm{CV}$, and making an action plan for emergencies for a young carer whose parent has epilepsy. Other actions included signposting for additional support or services that could be helpful. Interestingly, one staff member reported that completing the CAT-YC with a young carer made them realise that some of the issues raised could be addressed immediately, without much effort. Typical completion time for the first use of the CAT-YC was approximately $20 \mathrm{~min}$, although participants reported that this became quicker with increased use.

Participants recommended adding a reminder after the screening questions for staff to check whether there was anything else the young person wanted to talk about, or record for themselves on the CAT-YC. Space was therefore provided after the planning section for both staff and young carers to make notes or record pertinent information, if required. The CAT-YC is free to use by non-profit organisations and will be available for dissemination and use with supporting guidance from the project website, following a larger validity pilot currently taking place.

\section{Discussion}

The Delphi findings present a consensus view from young carers and professionals on the needs that can present the most challenges to young carers. The CAT-YC was developed using a multi-phased approach capturing the views of young carers and a wide range of professionals from health, social care and education settings. This breadth of experience makes the development of the CAT-YC distinct from other screening tools, which have relied primarily on data from one source, or have been adapted from established scales. One of the key strengths of this study has been the involvement of young carers throughout every stage of the process, from informing the study materials to taking part in a focus group, individual interviews, consensus group meetings, online surveys and commenting on and providing feedback about the key findings in the consultation phase (Shaw et al., 2011; Phelps, 2017). This is important to note, as existing literature suggests that such active involvement of service users in the research process can have a positive impact on outcomes, by ensuring its appropriateness and relevance (Brett et al., 2014; Dovey-Pearce et al., 2019).
Importantly, the CAT-YC can be used in a multitude of settings by a range of professionals to initially identify young carers. This may be particularly useful for professionals who do not work exclusively with young carers, e.g. school staff, social services and health care practitioners. This corresponds to findings from a study involving 800 teachers, whereby almost half of the respondents said they did not feel confident they could recognise a young carer (Barnardo's, 2017). It can also be used not just to screen for needs arising from a young carer's role, but also for ongoing review and monitoring purposes. A potential benefit of this could lead to providing more targeted resources and support. It may also help identify if there are potential safeguarding issues that need consideration, which in the UK should automatically trigger the legal requirement to conduct a full needs assessment by a qualified social worker (Local Government Association, 2018).

Despite the range of roles and perspectives of the panel members, there was a high level of consensus on the key items to be included in the CAT-YC. The first five key items relate to the overarching theme of the young carers' situation and caring role within the family home. These focus on: the types of care tasks undertaken; tasks that they may not want to do; who to contact in an emergency; giving or checking medication; and whether they support or provide care for anyone else in the family. The second five items relate to the overarching theme of the young carers' own health and social wellbeing. These focus on: whether they need help speaking to someone about getting support with their caring role; whether they feel bullied or lonely because of their role; their own health or emotional wellbeing; if they need a break or time away from their caring role; if there is anything stressful about school or college, or stressful generally. The importance of these items is similarly reflected in existing literature (Dearden \& Becker, 2004; Warren, 2007; Aldridge et al., 2016; Cheesbrough et al., 2017; Kettell, 2020).

A common theme throughout the development of the CAT-YC has been the importance of early intervention and the role that all services that work with young carers have in identifying, assessing and supporting them, so they have the best opportunities to flourish. For young carers, the potential benefits from using the CAT-YC are that it makes the screening process visible, promotes autonomy by engaging them in making an action plan together, and consequently legitimises their support needs. For parents or guardians, the potential benefits are likely to come from knowing their child is being supported, reassurance that others are aware of the caring situation and are trying to help, and are engaging as part of a whole family approach. For individual practitioners, the potential benefits of using the CAT-YC are likely to come from being proactive in trying to avert a crisis, or recognising when a safeguarding referral needs to be made. For organisations, the CAT-YC will provide a clear record of 
activity that will assist with accountability, generate statistical data for auditing and communication purposes, and help establish which interventions are most effective. This in turn will help when planning resources and service delivery, as well as providing information that may be strategically useful for funding purposes.

The CAT-YC will also allow comparisons to be made between young carers and their peers, as it will focus on the impact from caring, thereby differentiating between the type of everyday helping carried out by many young people, and those in a caring role. Moreover, monitoring the number and nature of referrals made will not only provide useful statistical data, but may aid understanding as to which interventions have been most or least effective.

\section{Limitations}

The sample of participants in the qualitative phases of the Delphi survey were from one geographical area in the UK, which could be perceived as a weakness of the design. It is possible that cultural or ethnic differences of the participants could impact on the validity and reliability of the CAT-YC and this issue will be considered in further development of the tool during the pilot study. However, the participants came from very different localities, including some areas of deprivation, within the geographical area. Furthermore, an unexpected positive finding from this phase came from interviewing six participants who were not part of a dedicated young carers' service. This provided new information not previously reported in the literature and will be reported in a separate paper. Furthermore, in subsequent Delphi rounds, participants were from every region in England, as well as from Scotland, Wales, Eire, Canada and the USA, thereby enhancing generalisability (Bryman, 2016).

Additionally, although a brief pilot study was undertaken to test readability and usability, findings from a larger longitudinal pilot study currently taking place will need to be reported to establish validity and reliability. Nevertheless, two frameworks were used during the development of the CAT-YC to systematically support and evaluate the quality and rigour of how the study was conducted and reported: the first based on guidance on conducting and reporting Delphi studies (CREDES) (Jünger et al., 2017); the second based on the consolidated criteria for reporting qualitative research (COREQ) (Tong et al., 2007).

\section{Conclusion}

The CAT-YC is an evidence-based identification and screening tool, consisting of ten prioritised questions, that can be used in a number of settings by different health, social care and educational professionals who work with young people.
This could include keyworkers in drug and alcohol support services, or Child and Adolescent Mental Health Services. In particular, it will be useful for school and college staff to use as an aid to identifying previously unknown young carers. This will not only benefit the individual young carers, who can then be screened and triaged for support, but by establishing the prevalence of young carers within an educational setting, it may additionally aid understanding of why so many continue to remain hidden. As a society, we have a duty to support these young people. The urgent need to undertake regular triage to identify their needs and adequately support them cannot be underestimated. Although developed in the UK, the CAT-YC has the potential to be adopted internationally and across a range of settings. Further information about the CAT-YC is available at the project website: https://www.edgehill.ac.uk/carers/

Acknowledgements We wish to thank the young carers and professionals who shared their experiences and views on the development of the CAT-YC.

Funding The authors received no financial support for the research, authorship, and/or publication of this article. The corresponding author's doctoral study was funded by Edge Hill University.

\section{Declarations}

Conflict of interest The authors declared no potential conflict of interest with respect to the research, authorship, and/or publication of this article.

Ethical Approval Prior to commencement, ethical approval for all phases of the study was granted by the University and local Research Ethics Committees.

Consent to Participate Informed consent and assent were obtained from participants throughout the study phases.

Open Access This article is licensed under a Creative Commons Attribution 4.0 International License, which permits use, sharing, adaptation, distribution and reproduction in any medium or format, as long as you give appropriate credit to the original author(s) and the source, provide a link to the Creative Commons licence, and indicate if changes were made. The images or other third party material in this article are included in the article's Creative Commons licence, unless indicated otherwise in a credit line to the material. If material is not included in the article's Creative Commons licence and your intended use is not permitted by statutory regulation or exceeds the permitted use, you will need to obtain permission directly from the copyright holder. To view a copy of this licence, visit http://creativecommons.org/licenses/by/4.0/.

\section{References}

Aldridge, J. (2014). YC-QST-20: Young carer screening tool and questionnaire. Loughborough University. 
Aldridge, J. (2017). Introduction to the issue: Promoting children's participation in research, policy and practice. Social Inclusion, 5(3) 89-92. https://doi.org/10.17645/si.v513.1157

Aldridge, J., \& Becker, S. (1997). Prevention and intervention: Young carers and their families. Young Carers Research Group, Loughborough University. http://www.lboro.ac.uk/departments/ss/centr es/YCRG/

Aldridge, J., Clay, D., Connors, C., Day, N., \& Gkiza, M. (2016). The lives of young carers in England. TNS BMRB. https://www.gov. uk/government/uploads/system/uploads/attachment_data/file/ 498115/DFE-RR499_The_lives_of_young_carers_in_England. pdf

Bailey, S., Boddy, K., Briscoe, S., \& Morris, C. (2015). Involving disabled children and young people as partners in research: A systematic review. Child Care, Health and Development, 41(4), 505-514. https://doi.org/10.1111/cch.12197

Barnardo's. (2017). Still Hidden, Still Ignored. Who cares for young carers? http://www.barnardos.org.uk/still_hidden_still_ignored_ barnardo's_young_carers_report

Becker, S., \& Sempick, J. (2018). Young adult carers: The impact of caring on health and education. Children \& Society, 12, 1-10. https://doi.org/10.1111/chso.12310

Braun, V., \& Clarke, V. (2006). Using thematic analysis in psychology. Qualitative Research in Psychology, 3(2), 77-101.

Brett, J., Staniszewska, S., Mockford, C., Herron-Marx, S., Hughes, J., Tysall, C., \& Suleman, R. (2014). Mapping the impact of patient and public involvement on health and social care research: A systematic review. Health Expectations, 17(5), 637-650.

Bryman, A. (2016). Social Research Methods. (5th ed). Oxford University Press.

Carduff, E., Finucane, A., Kendall, M., Jarvis, A., Harrison, N., Greenacre, J., \& Murray, S. A. (2014). Understanding the barriers to identifying carers of people with advanced illness in primary care: Triangulating three data sources. BMC Family Practice, 15, 48. https://doi.org/10.1186/1471-2296-15-48

Carers UK. (2016). Carers and their rights. England. (6th Ed). Carers UK.

Cheesbrough, S., Harding, C., Webster, H., \& Taylor, L. (2017). The lives of young carers in England. https://assets.publishing.servi ce.gov.uk/government/uploads/system/uploads/attachment_data/ file/582575/Lives_of_young_carers_in_England_Omnibus_resea rch_report.pdf

Children's Commissioner. (2016). Young Carers. The support provided to Young Carers in England. https://www.childrenscommissioner. gov.uk/wp-content/uploads/2017/06/Young-Carers-report-Decem ber-2016.pdf

Dearden, C., \& Becker, S. (2004). Young carers in the UK: The 2004 report. Carers UK and The Children's Society.

Department of Health. (2014). Care and support statutory guidance. London: Department of Health. https://assets.publishing.service. gov.uk/government/uploads/system/uploads/attachment_data/file/ 315993/Care-Act-Guidance.pdf

Dovey-Pearce, G., Walker, S., Fairgrieve, S., Parker, M., \& Rapley, T. (2019). The burden of proof: The process of involving young people in research. Health Expectations, 22(3), 465-474.

Elo, S., \& Kyngäs, H. (2008). The qualitative content analysis process. Journal of Advanced Nursing, 62(1), 107-115.

Field, A. (2013). Discovering statistics using IBM SPSS. (4th ed.) Sage Publications Ltd.

Gaffney, M. (2007). A research study of young carers: The development of a recording tool for agencies to identify young carers. Wellington: Ministry of Health (in association with Carers NZ). http://www.health.govt.nz/publication/research-study-young-carers-development-recording-tool-agencies-identify-young-carers
Gibson, F. (2007). Conducting focus groups with children and young people: Strategies for success. Journal of Research in Nursing, 12(5), 473-483

Green, J., \& Thorogood, N. (2014). Qualitative methodology and health research. Qualitative Methods for Health Research, 3-26.

Hsieh, H.-F., \& Shannon, S. E. (2005). Three approaches to qualitative content analysis. Qualitative Health Research, 15(9), 1277-1288. https://doi.org/10.1177/1049732305276687

Hunt, K., \& Lathlean, J. (2015). Sampling. In K. Gerrish \& J. Lathlean, (Eds.) The Research Process in Nursing (pp. 172-183). (7th ed.) Wiley Blackwell.

IBM Corp. Released 2017. IBM SPSS Statistics for Windows, Version 25.0. Armonk, NY: IBM Corp.

Jünger, S., Payne, S. A., Brine, J., Radbruch, L., \& Brearley, S. G. (2017). Guidance on Conducting and Reporting DElphi Studies (CREDES) in palliative care: Recommendations based on a methodological systematic review. Palliative Medicine, 31(8), 684-706. https://doi.org/10.1177/02692163179690685

Kavanaugh, M. S., Stamatopoulos, V., Cohen, D., \& Zhang, L. (2015). Unacknowledged caregivers: A scoping review of research on caregiving youth in the United States. Adolescent Research Review., 1(1), 1-21. https://doi.org/10.1007/s40894-015-0015-7

Keeney, S. (2015). The Delphi Technique. In: K. Gerrish \& J. Lathlean, eds. The Research Process in Nursing (pp. 266-277). (7th ed.). Blackwell Publishing Ltd.

Keeney, S., Hasson, F., \& McKenna, H. (2011). The Delphi Technique in Nursing and Health Research. Wiley-Blackwell.

Kettell, L. (2020). Young adult carers in higher education: The motivations, barriers and challenges involved - a UK study. Journal of Further and Higher Education, 44, 100-112.

Knighting, K., O’Brien, M. R., Roe, B., Gandy, R., Lloyd-Williams, M., Nolan, M., \& Jack, B. A. (2015). Development of the Carers' Alert Thermometer (CAT) to identify family carers struggling with caring for someone dying at home: A mixed method consensus study. BMC Palliative Care, 14(1), 1-13.

Knighting, K., O'Brien, M. R., Roe, B., Gandy, R., Lloyd-Williams, M., Nolan, M., \& Jack, B. A. (2016). Gaining consensus on family carer needs when caring for someone dying at home to develop the Carers' Alert Thermometer (CAT): A modified Delphi study. Journal of Advanced Nursing, 72(1), 227-239.

Leu, A., \& Becker, S. (2017). A cross-national and comparative classification of in-country awareness and policy responses to 'young carers.' Journal of Youth Studies., 20(6), 750-762.

Local Government Association. (2018). Meeting the health and wellbeing needs of young carers. http://www.local.gov.uk/bright-futures

Malcolm, C., Knighting, K., Forbat, L., \& Kearney, N. (2009). Prioritisation of future research topics for children's hospice care by its key stakeholders: A Delphi study. Palliative Medicine, 23(5), 398-405.

McDougall, E., O'Connor, M., \& Howell, J. (2018). Something that happens at home and stays at home: An exploration of the lived experience of young carers in Western Australia. Health \& Social Care in the Community, 26(4), 572-580. https://doi.org/10.1111/ hsc. 12547

McKenna, H. P. (1994). The essential elements of a practitioner's nursing model: A survey of clinical psychiatric nurse managers. Journal of Advanced Nursing, 19, 870-877.

McKenna, H.P., Hasson, F., \& Keeney, S. (2015). Surveys. In K. Gerrish \& J. Lathlean (Eds.). The Research Process in Nursing (pp. 254-265). (7th ed). Blackwell Publishing Ltd.

Moore, T., \& McArthur, M. (2007). We're all in it together: Supporting young carers and their families in Australia. Journal of Health and Social Care in the Community, 15(6), 561-568. https://doi.org/10. 1111/j.1365-2524.2007.00719.x/epdf 
Nagl-Cupal, M., Daniel, M., Koller, M., \& Mayer, H. (2014). Prevalence and effects of caregiving on children. Journal of Advanced Nursing, 70(10), 2314-2325. https://doi.org/10.1111/jan.12388

Nicholls, W., Patterson, P., McDonald, F. E. J., \& Hulbert-Williams, N. J. (2016). Unmet needs in young adults with a parent with a chronic condition: A mixed-method investigation and measure development study. Scandinavian Journal of Caring Sciences. https://doi.org/10.1111/scs.12320

Novakowski, N., \& Wellar, B. (2008). Using the Delphi technique in normative planning research: Methodological design considerations. Environment and Planning A, 40, 1485-1500.

Pakenham, K. I., Chui, J., Bursnall, S., Cannon, T., \& Okochi, M. (2006). The psychosocial impact of caregiving on young people who have a parent with an illness or disability: comparisons between young caregivers and noncaregivers. Rehabilitation Psychology, 51(2), 113-126.

Phelps, D. (2017). The voices of young carers in policy and practice. Social Inclusion, 5(3), 113-121.

Polit, D.F., \& Beck, C.T. (2017). Nursing Research: Generating and Assessing Evidence for Nursing Practice. (10th ed.). Wolters Kluwer Health.

Schurgin, O.K.G., \& Clarke-Pearson, K. (2011). Council On Communications and Media. Clinical report-the impact of social media on children, adolescents, and families. Pediatrics, 127, 799-804.

Shaw, C., Brady, L-M., \& Davey, C. (2011). Guidelines for Research with Children and Young People. http://www.participationworks. org.uk/

Siskowski, C. (2006). Young caregivers: Effect of family health situations on school performance. The Journal of School Nursing, 22(3), 163-169.
Stamatopoulos, V. (2018). The young carer penalty: Exploring the costs of caregiving among a sample of Canadian youth. Child \& Youth Services. https://doi.org/10.1080/0145935X.2018.1491303

Stewart, D.W., \& Shamdasani, P.N. (2014). Focus groups: Theory and practice, 20. Sage Publications Limited.

The Children's Society. (2013). Hidden from view: The experiences of young carers in England. http://www.childrenssociety.org.uk/ sites/default/files/tcs/report_hidden-from-view_young-carers_ final.

The Children's Society. (2016). Barriers and solutions to implementing the new duties in the Care Act 2014 and the Children and Families Act 2014. https://www.childrenssociety.org.uk/sites/default/files/ barriers-and-solutions.pdf.

Tong, A., Sainsbury, P., \& Craig, J. (2007). Consolidated criteria for reporting qualitative research (COREQ): A 32-item checklist for interviews and focus groups. International Journal for Quality in Health Care, 19(6), 349-357.

UK Council for Child Internet Safety. (2016). Child Safety Online. A Practical Guide for Providers of Social Media and Interactive Services. https://www.gov.uk/government/uploads/system/uploa ds/attachment_data/file/487973/ukccis_guide-final_33_pdf.

Warren, J. (2007). Young carers: Conventional or exaggerated levels of involvement in domestic and caring tasks? Children \& Society, $21,136-146$.

Publisher's Note Springer Nature remains neutral with regard to jurisdictional claims in published maps and institutional affiliations. 